Revista Iberoamericana, Vol. LXXI, Núm. 210, Enero-Marzo 2005, 189-201

\title{
MEMORIA Y MEMORIAL EN DOÑA INÉS CONTRA EL OLVIDO DE ANA TERESA TORRES
}

\author{
POR \\ SUSANA ZANETTI \\ Universidad de Buenos Aires \\ Universidad Nacional de La Plata
}

\begin{abstract}
Yo estoy aquí para recordar el final de la guerra que emprendimos y cantar su victoria, y a pesar de mi miseria, guardo la esperanza de que algún día vendrá alguien a poner la casa en pie y algún día yo encontraré los títulos que se me perdieron
\end{abstract}

Doña Inés contra el olvido (75)

NARRAR LAS IDENTIDADES

El recuerdo y la memoria, ceñidos a la proyección de una vida a través de la voz perdurable de un fantasma, pocas veces se impregnan en Doña Inés contra el olvido de la esperada nostalgia por las pérdidas que circundan toda rememoración, pues interesa aquí sobre todo derivarlos hacia el alegato, un alegato concreto sobre la propiedad de la tierra y un alegato en una dimensión simbólica, por la preservación de la memoria colectiva, contra las políticas de la desmemoria, que se nos presenta sólidamente ligado al primero. Si su centro es el hogar, la casa, es decir, el núcleo de la ilusión de permanencia y de identidad a través de la herencia familiar, del linaje, la voz de Doña Inés, una mantuana orgullosa de su estirpe, se expande a la vida pública para poner en escena los resortes que movilizan y dan soporte a la sociedad nacional o quizás, dicho de manera más discreta, a su mera posibilidad.

La obsede escudriñar el pasado, a partir de un tratamiento en el cual la petite-histoire, el "diario ajetreo", se magnifica precisamente por esa fusión que desdibuja las fronteras de lo que se juzgaba relevante o, más bien, lo complejiza y pluraliza con la inmediatez de la experiencia aparentemente menuda, de sentimientos, gozos, luchas, de individuos anónimos, difíciles de rescatar del polvo que ha sellado sus tumbas.

El alegato deriva así desde lo individual -desde los intereses que concilian a sectores sociales originalmente enfrentados en la historia particular narrada- a otros planos, a aquellos en que una identidad colectiva se fragua en la confluencia de recuerdos transmitidos por quienes, pertenecientes a esas clases en pugna, pueden acordar en pro del bien común y de este modo, aunque sea precariamente, sentar las bases de la sociedad nacional. 
En el breve artículo titulado "La voz autoritativa en las novelistas venezolanas contemporáneas”, ya aclaraba Ana Teresa Torres, avalada por el ejemplo de Solitaria solidaria (1990) de Laura Antillano, cómo contar la historia venezolana sin obedecer a preconceptos sobre la percepción y la sensibilidad femeninas. Con las perspectivas escogidas por su compatriota refuta toda "idea de que la mujer escritora es una guardiana del pasado y se presta a recoger en sus novelas las tradiciones, usos y costumbres” de un ámbito dado, con el fin de destacar que los personajes femeninos de esa novela desmienten la limitación en que se los quiere circunscribir, negando la conservación pasiva y acrítica de modos de ser para afirmar que a través de la experiencia adquieren una progresiva autoconsciencia de sí que no sólo transforma su mirada sobre la vida social y política, sino que decide las maneras de actuar en ella (56-7); al mismo tiempo la autora de Solitaria solidaria convalida la legítimidad de la ficción para intervenir en la disputa entre las versiones que sustentan la inteligibilidad y los sentidos del pasado venezolano, convencida, como Jacques Rancière, de que:

... siempre es posible atribuir acontecimientos verídicos a sujetos de ficción o de sustitución, y acontecimientos inciertos y ficticios a sujetos reales. La historia recreativa y la novela histórica se nutren en los pliegues y repliegues que autorizan esta indeterminación. (10)

Unos años antes, en 1991, esa misma novela había auxiliado a Ana Teresa Torres a enmarcar su narrativa a partir del balance expuesto en "El escritor ante la realidad venezolana”, signada por "una devaluación no sólo económica sino también política y ética” resultante de las sucesivas crisis de los sesenta y setenta, que la protagonista de Antillano procuraba restañar mediante la investigación del pasado (una tesis sobre la etapa de Guzmán Blanco), trabajo entrevisto por Torres como "expresión de una desilusión generacional que se siente sin proyecto compartido, sin posibilidad de relevo y sin otro camino que el escepticismo" (41) que lleva "a una lucha entre el deseo de olvidar y a la vez de recordar" en la que triunfa finalmente "la escritura que da lugar a la rememoración" (41).

En consonancia con sus pares, Torres también había interrogado a la historia nacional recurriendo a la novela. Ya El exilio del tiempo (1991) ponía en escena una crisis que no la ha abandonado pues sesga, intensificándose, su obra posterior, desde Doña Inés contra el olvido a Los últimos espectadores del acorazado Potemkin (1999). En ellas encarnan las reflexiones recién mencionadas sobre la narrativa de sus contemporáneos, espejo evidente de la propia, en cuanto a los modos de representar y de significar los estrechos lazos entre la pluralidad de memorias colectivas y las marcas que ella deja en la plasmación de una identidad nacional:

... pienso que hay en estas novelas una mirada de angustia hacia el país, una evocación de sus señas de identidad, y un deseo de reasegurar la voz de los anónimos que han configurado su textura social y que de alguna manera le han dado consistencia; un alegato por una huella de identidad que no quiere diluirse en la fragmentariedad de una imagen que pudiera, por un instante, hacernos creer que se trata de un país solucionado. (42) 
Sin dudas estas preocupaciones presiden su mirada a la Historia en la novela que consideramos. Pero las urgencias por diseñar asideros para el futuro incierto eluden en Doña Inés contra el olvido el tratamiento de la memoria ligada a las fábulas de los orígenes nobles de la nación, tanto como las pretenciones de coherencia del desarrollo histórico mediante una concatenación teleológica, irónicamente indicada aquí en la sucesión de promesas incumplidas de los sucesivos gobiernos venezolanos. La concordancia entre pasado, presente y futuro entroniza desilusiones, pesimismo y escepticismo, intensificados simbólicamente por la fuerza corrosiva del tiempo, acentuada por la muerte como inicio o como fin de muchos capítulos de la novela.

A medida que avanza la década de los noventa corroboraba Ana Teresa Torres su preferencia por la memoria y la autobiografía como ejes de su narrativización de la historia nacional, ligadas a la reconstitución de identidad, de solución difícil en Vagas desapariciones (1995), o sustentadas en el humor desenfadado, como ocurre en Malena de cinco mundos (1997), perspectivas expresadas además en la conferencia citada por Gloria Da Cunha-Giabbai:

No es un tiempo de nostalgia el que evoco, ni una aspiración a restaurar el pasado. Es la búsqueda de una memoria que nos falta. La memoria apoya cierta continuidad de nosotros mismos, nos da cierta existencia en contra de las erosiones del tiempo y la permanente disolución de la identidad. (62-3)

Es justamente “en este país de la desmemoria” donde se instala el descarnado fantasma de Inés Villegas y Solórzano, protagonista y narradora de Doña Inés contra el olvido. Mientras busca y cita afanosamente autos, reales cédulas y legajos probatorios de la propiedad de sus tierras en constante litigio, confiesa apenas iniciada la narración "Yo quiero que mi voz permanezca” (12), e insistirá a lo largo de ella sobre el sentido de la rememoración, su "baluarte” (134) como la llama, edificado en la soledad y el abandono en que ha quedado a la muerte de los suyos.

Los avatares del pasado venezolano se van conformando desde las versiones del pleito contado en esta suerte de autobiografía femenina que se proyecta sin hiatos casi y sin pausas en la saga familiar.

LA MEMORIA DE UN ESPECTRO

Estamos ante una autobiografía singular, porque surge del tenaz monólogo, que Doña Inés pretende diálogo, con su marido Alejandro Martínez de Villegas y Blanco y con su “esclavo y liberto” Juan María del Rosario Villegas, ambos tan muertos como ella, muertos "mudos”, como repetidamente los define. Y porque el pasado que la voz narrativa construye se desliza en los bordes del incierto pasaje del presente hacia el pasado y hacia el futuro, podríamos decir con un tratamiento cercano al analizado por Reinhart Koselleck en Futuro pasado, que contribuye a indeterminar la constante escena del diálogo mencionado, al movilizar complejamente el presente de la enunciación, dado que la oralidad proviene de momentos fabulados que involucran el pasaje a la escritura, pues el relato de Doña Inés se trama al compás de esos documentos dictados para que alcancen su función legal. 
Conviene apuntar antes qué hechos desatan el pleito. Doña Inés ciñe el relato a la historia de su familia, fundamentamente la de la descendencia, tanto la propia como la de su oponente, Juan María del Rosario, desde 1715 hasta 1985, es decir, a lo largo de 270 años, al comienzo de los cuales cuenta ya su muerte, la de su marido y la del ex-esclavo, ocurridas hacia mediados del siglo XVIII. ${ }^{1}$ La motivación de lo narrado es la pelea por la recuperación de parte de las tierras de su hacienda de Curiepe, heredadas de su padre, perdidas primero en el litigio con Juan del Rosario -quien adujo que le habían sido donadas por don Alejandro, del cual es en realidad hijo bastardo-, y expropiadas en 1884, durante el gobierno del general Crespo, para destinarlas a la circulación de un ferrocarril, cuya construcción nunca se concluyó. Antes de la solución del litigio pasan a ser explotadas por la Cocotera Aguasal de capital extranjero.

Nuevamente la ficción histórica se vale de lo escondido, de lo oculto, a partir de la representación de la búsqueda o el hallazgo de documentos, generalmente arrumbados en desvanes y gavetas, que complejizan lo conocido, lo desmienten o lo revierten. Imaginariamente la novela de Torres diseña un nuevo archivo, cuyo propósito va más allá de la simple permanencia. El recuerdo y la memoria se plantean operando en otras dimensiones: en el diseño de las identidades y de la integración nacionales, a partir de uno de los lugares funcionales de la memoria colectiva definidos por Pierre Nora en Les lieux de la memoire, como son las autobiografías, en el sentido, y es pertinente el recuerdo de esta perspectiva, pues Doña Inés contra el olvido pone en escena los usos que hacen de la memoria colectiva los productores y dominadores, insertos en experiencias históricas y en medios sociales y políticos determinados.

La recomposición del archivo requiere que Doña Inés convierta su voz en escritura, acudiendo a ese escribano al que dice dictarle sus demandas (pues apenas aprendió a escribir) en tanto escudriña ansiosa los recovecos de la casa en busca de los papeles extraviados. Esta dirección encarrila la historia individual en la confianza en la ley y en la legalidad que establece la escritura, una confianza aparentemente ingenua pues el personaje conoce muy bien, y lo recalca constantemente, el poder que le da su condición social y económica de mantuana (a la vez sometida a un orden sexual del cual precisamente proviene ese poder). Por esta vía el tema se abre a lo social, a los conflictos originados por la esclavitud, ${ }^{2}$ a cuestiones de género sexual, proyectados a la dimensión nacional a través del acento puesto en la oscura trama entre el poder y la ley en el pasado, acento que, por otra parte, impregna con fuerza la novela venezolana, tan sólo si pensamos en Rómulo Gallegos o en Arturo Uslar Pietri.

Y aquí estoy, Alejandro, acariciando los rincones de mi casa de San Jacinto, contenta de ver que han limpiado sus manchones y pintado sus paredes, contemplando sus cortinas nuevas y compuestos sus mosaicos, alegre de oír otra vez el agua que surte el pozo y brinca en la pila del patio, gozosa de sombrearme bajo el guayabo del corral y de descansar en

${ }^{1}$ Doña Inés muere el 23 de abril de 1781.

${ }^{2}$ Unidos aquí a la promiscuidad del amo mediante el sometimiento sexual de las esclavas, como evidencia la sospecha de Doña Inés acerca de que su marido es el verdadero padre de Juan del Rosario. 
la penumbra que invade mis corredores. A pesar de tantas noticias y calamidades, aquí estoy buscando mis títulos, encorvada, rastreando en los arcones, levantando las alfombras ... (87)

Esta obsecada búsqueda constituye el motor de las acciones de la narradora y de su supervivencia más allá de la muerte. Si bien es cierto que la novela vuelve innegables los vínculos entre intimidad, ámbito privado y vida pública, presentados habitualmente como básicos en la constitución del mundo y de la escritura femeninos a través de esos géneros enamorados de lo secreto (la autobiografía, los diarios íntimos o las cartas); también es cierto que se destaca aquí que lo secreto, lo arrumbado, lo olvidado, se propone decididamente romper el encierro (el doméstico y el de la voz femenina) y ser divulgado, proclamado, actuar como discurso de confrontación por encima del límite más o menos anodino y convencional del pleito para dar otra vuelta de tuerca a la interpretación de la historia nacional.

La articulación de lo que se nos cuenta es modulada por la voz narrativa a través de movimientos temporales que, si bien atentos a la cronología, irónicamente marcada, se desplazan sometiendo las distancias entre presente, futuro y pasado. El recuerdo obedece a los intereses del litigio y de la continuidad de la estirpe, de manera tal que la introducción, fragmentada muchas veces, de las historias de los personajes involucrados, se pliega al discurso imperativo de Doña Inés, quien no sólo quiere contar lo que ha sucedido, acaba de suceder o está sucediendo sino también dirigir en lo posible los acontecimientos. De allí que el recuerdo se abrace al presente siguiendo al futuro.

En este sentido configura una afirmación de la vida aunque hay un poderoso ritmo narrativo escandido por la muerte, los cortejos fúnebres y la descomposición (de los cuerpos, de los proyectos republicanos), ritmo narrativo que permite destacar la energía femenina, pues es un cadáver, un fantasma en pedazos quien subsiste para testimoniar y preservar la memoria, a la que siente como savia capaz de nutrir la existencia de la nación tanto como su voz apuntala la perduración de la vida, significación que se aparta de implicaciones esencialistas sobre lo femenino, al ampliar y complejizar los sentidos de “dar y preservar la vida”. El significativo topos de la casa, que había sido referencia de peso en la primera novela de Ana Teresa Torres, es imagen viva a su vez de la destrucción repetida y de la desmemoria que corroe a la sociedad venezolana, a partir del terremoto de 1812 y de la entrada de Boves y de las tropas realistas en 1814:

Han pasado los años y no ha habido manos que recojan las piedras que cayeron ese día ni levanten las casas derrumbadas, porque Caracas es una ciudad de espectros. (74)

Doña Inés, tozudamente entregada a cruzar las fronteras que le fueron vedadas en vida, es uno de ellos. Estamos ante un fantasma, ese presente-no-presente, esa sobrevivencia de un resto del pasado, que con razón considera Jacques Derrida en Espectros de Marx un trauma o una herencia, una pérdida que, si bien dejó de estar, vuelve, regresa en el presente para perturbarlo, para convertirse en portavoz de un grupo social y un linaje. El pasado aquí vive en el presente como puesta en escena de la memoria pensada como nunca definitivamente consolidada, como en proceso continuo de transformación y de 
reactualización. Por momentos, el carácter imperativo de esta voz subraya que los muertos pueden ser más poderosos que los vivos, pero siempre advierte el desvarío de pretender toda totalización racional del pasado.

EL NACIMIENTO DE UNA IDENTIDAD PRECARIA

Mi vida fue atravesar mañanas lentas, días largos que el tiempo recorría despacio, vigilar el trabajo de las esclavas, verlas barrer las lajas de los patios, dar lustre a las baldosas y azulejos que hice traer de Andalucía ... (11)

La pausada siesta colonial, descrita en el inicio de la novela recién citado, destaca el peso de los criollos a través de la soberbia de la mantuana, ${ }^{3}$ sin que ningún acontecimiento notable señale el origen del linaje familiar o el de clase, pues se clausura cualquier atisbo de epicidad al transferir la violencia (y su idealización mediante los artilugios del coraje) al papeleo jurídico, inoperante por el embrollo de las distancias entre Caracas y la Metrópolis.

El pleito reemplaza el enfrentamiento heroico. Lo que estará en juego a lo largo de toda la historia contada son intereses y rivalidades, cuyo trasfondo es la propiedad de la tierra en esa Venezuela que Doña Inés define, en los años de la Revolución Legalista de Joaquín Crespo, como una "gran hacienda" (108). ${ }^{4}$ Focalizada desde los costos de vida y bienes, la fundación de la república es el único momento de la historia nacional valorado en la novela:

Como todo sueño quedará maltrecho, se nos caerá en andrajos, se burlarán de nosotros y nos taparemos con las manos la vergüenza de la desnudez, pero hemos echado a volar el fantasma de la emancipación que recorrerá el mundo y volverán a crujir las sillas en las que se sienta Europa. (49)

Las guerras de la Independencia se visualizan, por una parte, como guerra social representada desde la heterogeneidad étnica y los enfrentamientos de clase:

Adonde quiera que mirara encontraba los despojos que habían dejado las teas ardientes de los esclavos fugados al monte que caían sobre los poblados, hambrientos y desarrapados,

${ }^{3}$ Un ejemplo: “¿De modo que no los estorbe yo y no que ellos no me estorben a mí? Una sola cosa te digo, Carlos Tercero, y es que esto no se queda así, porque los mantuanos estamos de la Corona hasta la coronilla" (43).

${ }^{4}$ Joaquín Crespo, quien encabezó esa revolución en 1892, gobernó Venezuela hasta su muerte, ocurrida en 1898 en la batalla de Mata Carmelera. Doña Inés concentra su relato en el placer que le produce el solemne entierro del caudillo en el capítulo “Epitafio al general Joaquín Crespo”. La cita completa aclara lo que venimos diciendo sobre la muerte y destrucción que satura el pasado venezolano: “¿Cómo convenciste a tus campesinos para que estuvieran dispuestos a morir por el legalismo? Les diste a beber de la tacamajaca de Ño’Leandro ... Bien buena debe ser ... para que esos campesinos hambrientos se monten a la mula y apuesten su vida a ese truco del legalismo que has inventado para ser dueño de esta gran hacienda que es Venezuela. Así corren tras la promesa liberal, y te siguen a ti como han seguido y seguirán a otros tantos y te acompañarán hoy: el día de tu muerte”. 
arrasando a sangre y fuego, y tras ellos los soldados del general Arismendi, matando sin piedad a cuanto negro arrochelado encontraran, persiguiéndolos sin tregua en la selva hasta dar con alguno que degollar y pasear su cabeza pinchada en una estaca como aviso a las bandas de peones vagantes, esclavos, manumisos y miserables aventados por las voces realistas en contra de los ejércitos patriotas. (53-4)

Por otra, este fracaso es punto de partida de los fracasos de los ideales revolucionarios, degradados luego por la inoperancia, la lucha facciosa o la corrupción de la dirigencia política.. Sin embargo, son estas guerras un oscuro sustento de identidad, cuyo núcleo es la violencia, la violación y el ensañamiento en la destrucción y la muerte, dado el episodio que la novela elige para detenerse. No son los triunfos o la celebración de la Campaña Admirable, ni tampoco el decreto de Guerra a Muerte, posible anclaje de identidad por la apelación al venezolano y su tajante separación del español. Se interpreta en cambio el nacimiento de la nación desde las víctimas, desde la crueldad de la guerra en la Emigración a Oriente de 1814, en la derrota de los ejércitos y su penosa huida de Caracas ante la invasión de Boves. El momentáneo pedido a una alianza con su enemigo en el pleito, Juan del Rosario, ${ }^{5}$ se proyecta con las guerras de Independencia, sobre todo en la detenida representación de la Emigración a Oriente, en el amasijo de inmundicias, de sangre y barro, en los cuerpos confundidos de negros y blancos, de amos y esclavos, de hombres y mujeres en un camino que lleva más a la muerte que a la salvación:

El cansancio de los más inermes irrita a los que todavía tienen fuerzas y esperanzas. Hacen una fogata y de mano en mano van pasando algunas botellas de aguardiente. Otros se alejan, y en las sombras buscan unas faldas para dejar entre ellas escurrir el semen y el miedo, hay más de cincuenta mujeres por hombre, sin contar a los que tiritan de fiebre y no pueden ni siquiera bajar de los carros para hacer sus necesidades. La pestilencia invade la noche y algunos que no han aguantado la sed han vaciado los charcos que inundan los estómagos de disentería. (61)

Esta confluencia que abría puertas a la identidad, no se enajena en la idealización del manipulado "sacrificio por la patria" como tampoco entroniza en los subalternos -en la barbarie, en la raza o en la ignorancia de negros y mestizos- la imposibilidad de construir un derrotero viable para la república. Lentamente se abre paso a otras respuestas de estos sectores, no sólo en su destino de tropa enganchada para las luchas de federales y conservadores, o para integrar los ejércitos del Mocho Fernández o de Cipriano Castro, sino también en una vida cotidiana signada por el abandono de los afectos o de la tierra natal así como en la articulación de una memoria colectiva que auspicia la militancia política o sindical, es decir, la elección de vías democráticas, propias de una república moderna. De estos grupos sociales proviene exclusivamente esta militancia en la novela.

La focalización se adhiere a la pertenencia de la voz narrativa en un proceso en el cual va percibiendo, a partir de las guerras de la independencia, la pérdida de poder de su clase

\footnotetext{
5 “Ayúdame a buscar, negro terco, porque tú también estás vivo en esta búsqueda. Yo tengo la razón que me da el pasado y tú la que te da el futuro; ya verás que el tiempo nos cubrirá a los dos completamente, pero yo los seguiré buscando porque tengo la voluntad de que permanezcamos en la memoria” (36).
} 
y raza, al tiempo que su condición de mujer anuda fuertes alianzas afectivas -y desigualescon esclavas y sirvientas, condición que, por otra parte, genera la oscura comprensión de vínculos de envergadura social y nacional. Sabe ahora que el destino de los suyos está ineludiblemente unido al de otros, con los que comparte la pérdida de bienes y hogares reiteradamente abandonados, quemados, vueltos esfuerzo estéril. Por eso encuentra nueva función a su memorial:

Quiero dictar mi historia desparramada entre mis recuerdos y documentos, porque en ella se encuentra mi pasado y el de muchos. (12)

Su largo monólogo tiende otros lazos al tramar estrechamente historias familiares ajenas con la propia. Guían este movimiento los derroteros aparentemente azarosos del proceso de sus reclamos de las tierras de Curiepe, tierras que no quedan en meros papeles aunque durante su vida nunca las haya conocido. Pues ya muerta Doña Inés sigue de cerca a quienes viven, luchan y trabajan en ellas, haciendo recalar el relato en los sectores populares provenientes de la esclavitud, relato centrado en las familias -la suyaatravesadas por el desarraigo y el abandono masculino que traen las guerras, cuya supervivencia quedaba en manos de las mujeres. Exclusiones e inclusiones perfilan estos vínculos teñidos con imaginarios de lealtades en un mundo de amos y esclavos marcado por la sumisión, el rencor y el enfrentamiento que desata con ímpetu la guerra de independencia, novelizados desde perspectivas muy distanciadas de las dicotomías de Las lanzas coloradas de Arturo Uslar Pietri, entre los sectores ilustrados blancos, y el de los mulatos y mestizos, así como de la sumisión y la enajenación de los personajes femeninos. Aquí coincide con las miradas actuales hacia el rol de las mujeres en las guerras civiles o en las de independencia, muchas de ellas responsables de la conservación de hogar e hijos, o de trabajar para proveer su alimento y, asimismo, de participar en la discusión o en la difusión de las ideas.

El espectro se acerca además a los otros por la preponderancia que da a los cuerpos, igualados por el sufrimiento y la destrucción que trae la muerte, tanto el suyo propio como el de su más odiado enemigo, Joaquín Crespo, por haberle expropiado la hacienda. ${ }^{6}$

En otro nivel, emerge un Estado burócrata, movido por las conveniencias de los funcionarios y de la dirigencia política, incapaz de promover (o por lo menos mediar) acuerdos o conciliaciones sociales y políticas: irónicamente se insiste en el hecho de que sin su intervención se produce el arreglo final del pleito, acordado con una empresa que trae a la escena la transnacionalización de la economía. Se trata en verdad, como dice la novela, de una “negociación”, circunscripta solamente a intereses que, si pueden ser

\footnotetext{
6 “Estoy aquí, en mi camisón de seda negro roto en hilachas, desgreñada, sucia, pestilente, escondida en mi cuarto, aguantando que de los huecos del tejado me caiga polvo, me mojen los aguaceros y me reseque el sol.” (71), puede ser un ejemplo de cómo se ve a sí misma. El siguiente es un fragmento de la larga descripción del cuerpo de Crespo cuando muere y de su posterior preparación para embalsamarlo: "Y allí rodaste por el suelo, tu guerrera se llenó de sangre, tus pantalones de tierra, tu sombrero de Panamá voló y tu manta blanca quedó pisoteada bajo los cascos del caballo. ... tienes la camisa blanca empapada en sangre que ya se ha secado y huele mal, tienes los pantalones blancos llenos de polvo y la bragueta manchada de orina, tienes el rostro cenizo y los ojos cerrados ...” (109).
} 
beneficiosos para los habitantes de Curiepe, es decir, si pueden alcanzar un asidero social positivo, no van más allá. No generan ni implican una integración social y cultural que suponga el descubrimiento y la comprensión del otro, como puede verse claramente en la actitud de Francisco Villaverde ante José Tomás, su aliado en la negociación, en el episodio que cierra la novela: el velorio de la abuela de este último, antigua sirvienta de Belén, descendiente de Doña Inés y tía de Francisco.

Pero la novela reordena y califica ese mundo social de acuerdo con la importancia concedida no sólo a la incidencia cada vez más creciente de la pérdida de poder de viejos grupos dominantes ante la irrupción de agentes sociales que se desplazan desde las guerras lideradas por los caudillos a la emergencia de nuevos movimientos políticos y sociales, en los cuales adquieren relevancia no sólo en cuanto intervienen en su organización y dirección, sino porque en cierto sentido esta acción parece auspiciada por la valoración de la memoria colectiva, eje que involucra también a tradiciones culturales populares.

En torno a Doña Inés se agrupan simbólicamente estos personajes del ámbito subalterno para recibir el relato o trasmitir el pasado nacional. Por su condición femenina y la resistencia a la exclusión de los asuntos públicos reglada para su sexo, Doña Inés integra oblicuamente ese mundo subalterno, del que la separa su clase y raza -distancias señaladas reiteradamente por ella-, pero al que la une la persistencia del reclamo y de la protesta, tanto como la importancia que concede a ese reservorio de sentido que es la mirada hacia el pasado desde la memoria.

En otro plano, hay una insoslayable alusión a un linaje femenino que ensayó la rebeldía sin atinar a discernir las estrategias para no ser doblegado. Doña Inés, ya en plena dictadura de Juan Vicente Gómez, le dice a su marido muerto que su tataranieta Belén Sánchez Luna se aburría, recurriendo al siguiente comentario: "Son mujeres muy livianas las de ahora, Alejandro, ¿¿sabías tú que las mujeres se fastidian?” (152). Nos sugiere así la relación con la renuncia al amor, a la sinceridad, al descubrimiento y desarrollo del conocimiento de sí y del mundo de María Eugenia Alonso, protagonista de Ifigenia. Diario de una señorita que escribió porque se fastidiaba (1924) de Teresa de la Parra, cuya frustración amorosa Belén parece restañar al restañar la propia en los encuentros clandestinos con León Bendelac, destacados especialmente porque es la única concesión que la novela hace al placer de los cuerpos:

Lo que ella entregaba en cada encuentro con León Bendelac era una mujer que Domingo Sánchez nunca había conocido, nunca había deseado, y en suma, nunca había poseído. (162)

El tratamiento de estos amores adulterinos tanto como la sanción débil que produce en Doña Inés -“¿Te extraña mi relato sin condena?” (164)- la obligan a una disculpa que no hace más que apuntar a la mostración constante en la novela del rol femenino en la supervivencia y en la perduración, en las que la energía necesaria para sostener la intervención más activa posible encuentra un motor firme en la importancia que los personajes dan a la memoria. Podríamos decir que la autora misma se incluye al asumir el legado de Teresa de la Parra. 
MEMORA E HISTORIA

Y a ti qué te parecen, Juan del Rosario, las conclusiones de los historiadores? Por esos papeles tú y yo peleamos veinte años y ahora son una curiosidad de coleccionista. (201)

La indiferencia o el cultivo del olvido merecen constante desprecio, porque son síntomas de culpa, como sucede con el marido de Belén, Domingo Sánchez, o simplemente de estupidez o de pasividad para enfrentar el presente: así califica Doña Inés a su descendiente Francisco Villaverde Blanco, "pobre tonto no quería recuperar el pasado" (189), porque éste será el inicio de la recuperación de las propiedades perdidas. Si, según apuntaba Ernest Renan, el olvido era un componente relevante en la constitución de la nación, en esta novela sólo auspicia el engaño, tanto en las “promesas olvidadas” de las sucesivas dirigencias políticas como en la articulación que éstas han promovido de la historia nacional.

Una de las múltiples cuestiones acerca de la construcción de la Historia puestas en juego en Doña Inés contra el olvido se refiere a la historiografía y a la inscripción de sus prácticas, un modo de confrontar la apelación que esa disciplina hace a la objetividad o a la verdad para desautorizar o colocar entre paréntesis las pretensiones de otros discursos. Y aquí se evidencia la significación dada a la memoria, especialmente a los relatos orales producidos en distintos ámbitos y ante auditorios de los dos sectores sociales enfrentados en el litigio. También desde este punto de vista la novela obedece a consignas actuales acerca de la necesidad de que la ficción del pasado latinoamericano no descuide la representación de las investigaciones (el tratamiento de acontecimientos y documentos), de las "fuentes" de que se vale el historiador, y destaque al mismo tiempo el papel de los sujetos (historiadores o personas ajenas a la profesión) que se encargan de ellas, que cuentan la Historia y cómo la cuentan (estrategias y procedimientos). Importa recalcar cómo se colocan estos personajes ante la historiografía y sus academias. Aquí se cuela la puesta en cuestión de la Historia Oficial, con sus múltiples resortes y modos de operar.

Aunque en el texto se citan obras inventadas como datos de la base histórica utilizada, en una carta personal la autora ha revelado que su fuente para el litigio de la viuda Catalina Martínez de Villegas, tal era el nombre real del personaje, fue Apuntes para la historia colonial de Barlovento de Lucas G. Castillo Lara. ${ }^{7}$ El tema pertenece a un episodio fundamental para la resolución del conflicto. Casualmente obtiene la recuperación del archivo que guarda la documentación un historiador ficticio, aficionado y marginal,

\footnotetext{
${ }^{7}$ Tomo la información de Cynthia Tompkins, “La re-escritura de la historia en Doña Inés contra el olvido de Ana Teresa Torres”, incluido en la compilación de Edith Dimo y Amarilis Hidalgo de Jesús. En nota aclara que estos datos le fueron enviados por Ana Teresa Torres, "además de textos de Gonzalo Araujo y notas de prensa de 1986, en las que se basó para enlazar la historia del pleito hasta el presente” (106). Más adelante especifica, también según datos y materiales proporcionados por la autora, que esta última fuente proviene de El Nacional y del libro Las tierras de Barlovento del estado de Miranda de Carlos González Araujo. Además le expresó que eran ficticias las fuentes mencionadas en la novela: Pleitos de la familia Villegas. Apuntes para la historia jurídica del siglo XVIII de García Ocando y La explotación cacaotera en la Venezuela colonial de Luis Alberto Rangel, así como lo eran las referencias al historiador Romero España.
} 
políticamente muy crítico, el abogado Heliodoro Chuecos Rincón, quien introduce en la novela los modos en que las instituciones legitiman, y manipulan, la verdad de la Historia y la exhaustividad del archivo:

Vea mi obra. Si estuviera publicada serían más de veinte volúmenes, pero permanece inédita por falta de medios. He hecho gestiones con muchas personas, me he dirigido a muchas instituciones, pero todo ha sido infructuoso, no me reconocen como a un verdadero historiador, no tengo títulos que me acreditan como tal, entonces no conceden valor a este trabajo. (191-2)

El recuerdo y la memoria, como ya señalé, son constituyentes fuertes del memorial, es decir, de una memoria en función de apelación pública. Esta actitud, a medida que avanza la narración y hasta el momento culminante que acabo de referir, acerca a los descendientes y los contrincantes y, en términos generales, a personajes de sectores opuestos: la insistencia en la demanda, que se proyecta hacia la entera vida social, aparece ligada a quienes también interpretan los sentidos que puede tener la transmisión del pasado. Generalmente los relatos sobre el pasado, que entremezclan experiencias y mitos o leyendas, contados por sus mayores a niños y muchachitos, cumplen una importante función docente en la que se resalta la corrección o la presentación de otros intereses y de otros conocimientos dignos de conservarse, frente a las lecciones de la escuela. Un ejemplo lo proporciona esta referencia sobre la cocinera de Belén, la cual también narra el pasado, realzado por fantasías, a sus sobrinos:

Cuando Vicenta era niña, poco antes de conocer a Ernestino, los mayores se reunían las noches de los sábados, terminada la faena, y ella, sentada en el suelo, les escuchaba narrar casos, historias, moralejas y cuentos, mientras bebían, y a través de sus relatos comprendía cómo era la vida y el destino de los hombres ... (206)

Expresamente José Tomás, militante sindical y político, perteneciente a la línea de reclamos de herederos de esclavos y libertos, comparte con Doña Inés, origen de la línea opuesta, similar actitud ante el pasado y similar persistencia en el reclamo, como puede verse en el peso que han tenido las narraciones históricas oídas en su infancia:

“a mí me gusta más la democracia, padrino, que todo el mundo respete y obedezca las leyes”, le decía el muchacho. Sin embargo, su admiración no tenía límites al escucharlo recordar los sucesos que a su vez había escuchado a los otros; le parecía que aquélla si era la historia verdadera, no la que había recitado de niño para su maestra. (210)

También, frente a las referencias generales al plano político y a la dirección del Estado, la historia contada pone de relieve una sociedad sin herederos masculinos capaces de cumplir con los ideales “originales” de la república, cada vez más próxima a la esterilidad, presente en ese linaje aristocrático menoscabado por precarias alianzas matrimoniales. Si la emancipación no resulta cuestionada, los proyectos de constitución de un estado moderno muestran continua degradación. De allí que irónicamente la novela 
registre las “invenciones” en la esfera pública (la democracía, la dictadura, etc.), el mundo de las nuevas ideas concretadas sólo en las promesas de los discursos, en tanto que las mujeres, limitadas por su condición de tales a la protección y al encierro en el hogar, según criterios patriarcales, quedan a cargo de mantener la vida, si damos a esta función un fuerte carácter público, es decir, si con la novela la mirada se detiene en el modo en que pesa la actividad femenina en asuntos económicos y sociales, junto a la conciencia de los procesos, y los enjuagues, políticos.

La mirada de Doña Inés resalta la repetición y la pérdida, pues la modernización y la riqueza del suelo venezolano no traen el bienestar general esperado y posible... Se insiste en la violencia y la destrucción como resultado de la lucha política, mientras los intereses sectoriales se resuelven con la "negociación” comercial. Cuando la voz de Doña Inés definitivamente calla pues se acabó su pleito, calla también porque, a pesar de que surja a cada paso la evocación, siente finalmente que "acaso la memoria sea la más inútil de nuestras cualidades” (238). Desfallece así la confianza depositada en los recuerdos y en los testimonios de un proceso que ha impedido a los sujetos que actuaron en él y lo sufrieron una identificación colectiva como soporte de un proyecto común, como fundamento de la idea de nación. La atención puesta en la perspectiva genealógica se vuelve evidente, entre otros rasgos ya señalados, en los cortes cronológicos, enunciados por los títulos de los capítulos de la novela, indiferentes a todo esfuerzo de cohesión. Este escepticismo, que desmonta la narrativa tradicional de la nación, no clausura sin embargo, dada la intensidad con que el acto de recordar satura el relato, la apuesta a la conservación del pasado, a las posibilidades que una memoria colectiva plural, cuidadosa de sus usos y manipulaciones, todavía puede significar para el presente.

\section{BiBLIOGRAFÍA}

Castillo Lara, Lucas. Apuntes para la historia colonial de Barlovento. Caracas: Biblioteca de la Academia Nacional de la Historia, 1981

Certeau, Michel de. La escritura de la historia. México: Universidad Iberoamericana, 1985.

Da Cunha-Giabbai, Gloria. Mujer e historia. La narrativa de Ana Teresa Torres. Caracas: Centro de Actividades Literarias El Tigre, 1994.

Derrida, Jacques. Espectros de Marx. Madrid: Trotta, 1995.

Dimo, Edith y Amarilis Hidalgo de Jesús, ed. Escritura y desafío. Narradoras venezolanas del siglo XX. Caracas: Monte Avila, 1996.

Foucault, Michel. Microfísica del poder. Madrid: Planeta, 1994.

González Araujo, Carlos. Las tierras de Barlovento del estado de Miranda. Caracas: Editexto, 1987.

Koselleck, Reinhart. Futuro pasado. Para una semántica de los tiempos históricos. Barcelona: Paidós, 1993.

Nora, Piere. Les lieux de la mémoire. París: Gallimard, 1984.

Rancière, Jacques. Los nombres de la Historia. Una poética del saber. Buenos Aires: Nueva Visión, 1993. 
Rivas, Luz Marina. La novela intrahistórica: Tres miradas femeninas de la Historia venezolana. Caracas: Universidad de Carabobo, 2000.

T. Todorov. Los abusos de la memoria. Buenos Aires: Paidós, 2000.

Torres, Ana Teresa. A beneficio de inventario. Caracas: Memorias de Altagracia, 2000. Doña Inés contra el olvido. Caracas: Monte Avila, 1992.

"El escritor ante la realidad política venezolana”. Venezuela: fin de siglo. Julio Ortega, ed. Caracas: La Casa de Bello, 1993. 35-42.

“La voz autoritativa en las novelas venezolanas contemporáneas”. Revista Nacional de Cultura 301 (1996): 50-7.

“Mujer y sexualidad. La inserción de la mujer en el orden sexual”. Diosas, musas y mujeres. Caracas: Monte Avila, 1993. 37-47.

White, Hayden. Metahistoria. La imaginación histórica en la Europa del siglo XIX. México: Fondo de Cultura Económica, 1992.

El contenido de la forma. Narrativa, discurso y representación histórica. Barcelona: Paidós, 1992. 